\title{
WYKAZ PRAC DYPLOMOWYCH NAPISANYCH POD KIERUNKIEM KS. PROF. DRA HAB. FRANCISZKA DRĄCZKOWSKIEGO
}

\section{A. Prace doktorskie}

1. Grzywaczewski Józef ks., Modlitwa w duchu Agape według Klemensa Aleksandryjskiego, 1988.

2. Pałucki Jerzy ks., Chrystus Boski Lekarz, Wychowawca i Nauczyciel w pismach Klemensa Aleksandryjskiego, 1988.

3. Kowalski Aleksy ks., Obraz człowieka w ,Stromatach” Klemensa Aleksandryjskiego, 1991.

4. Paciorek Piotr ks., Pismo święte jako reguła wiary i moralności Kościoła na podstawie ,Enarrationes in Psalmos” św. Augustyna, 1991.

5. Rzodkiewicz Leopold ks., Chrystus przepowiadany Hellenom w pismach Klemensa Aleksandryjskiego, 1991.

6. Widok Norbert ks., Akamodacja misyjna w teorii i praktyce Klemensa Aleksandryjskiego, 1991.

7. Drążek Dariusz ks., Pojęcie disciplina w pismach św. Cypriana, 1994.

8. Szram Mariusz ks., Chrystus - Mądrość Boża wedtug Orygenesa, 1996.

9. Piątek Wojciech ks., ,Sprawiedliwy rozraduje się w Panu” $w$ interpretacji św. Augustyna zawartej w ,Enarrationes in Psalmos”, 1998.

10. Jaśkiewicz Grzegorz ks., Keryks - kerygma w mowach Grzegorza z Nazjanzu, 2001.

11. Zhyrkova Anna, Filozofia Jana Damasceńskiego w świetle „Pege Gnoseos”, 2002.

12. Zagórski Dariusz ks., Ideał mesotes $w$ pismach Klemensa Aleksandryjskiego, 2002.

13. Krempa Bogdan ks., Obraz człowieka Bożego w „Enarrationes in Psalmos” świętego Augustyna, 2006.

\section{B. Prace magisterskie i licencjackie}

1. Bidziński Kazimierz ks., Nauka o wstrzemięźliwości w traktacie „De continentia” św. Augustyna, 1984.

2. Głąb Marek ks., Patrystyczna wizja kapłaństwa na łamach „Ateneum Kapłańskiego" w latach 1909-1983, 1984.

3. Ignasiak Jan ks., Recepcja nauki Tertuliana i św. Cypriana na łamach „Ateneum Kapłańskiego"w latach 1909-1983, 1984.

4. Lis Sławomir ks., Nauczanie św. Augustyna o cierpliwości chrześcijańskiej w świetle dzieła „,De patientia”, 1985.

5. Mańka Ryszard ks., Zagadnienie pokuty w dziełach Tertuliana, 1985. 
6. Storczyk Stanisława, Model doskonałości chrześcijańskiej w „Mowach” Leona Wielkiego, 1985.

7. Bielak Jan ks., Rozumienie Kościoła w oparciu o dzieło św. Ambrożego „, Wykład do Ewangelii wedtug Łukasza”, 1986.

8. Denys Ryszard ks., Tytuły chrystologiczne w dziele św. Ambrożego „Expositio Evangelii secundum Lucam”, 1986.

9. Klimek Wiesław ks., Obraz Kościoła w Listach św. Cypriana, 1986.

10. Marianowski Leonard ks., Tytuły chrystologiczne w dziele św. Grzegorza Wielkiego „Homilie na Ewangelie”, 1986.

11. Prach Bogusław ks., Ideat kapłaństwa w ,Mowach” Grzegorza z Nazjanzu, 1986.

12. Rak Jacek ks., Komentarz do modlitwy „, Ojcze nasz” u Tertuliana, Ambrożego, Jana Kasjana i Piotra Chryzologa. Studium porównawcze, 1986.

13. Serej Józef ks., Komentarz do modlitwy ,,Ojcze nasz” u Maksyma Wyznawcy, św. Cypriana i Pseudo-Jana Chryzostoma, 1986.

14. Tabaka Aleksander ks., Zagadnienie modlitwy w „, Collationes Patrum” Jana Kasjana, 1986.

15. Ważny Bogdan ks., Program doskonalenia chrześcijańskiego $w$ „Homiliach na Ewangelie” św. Grzegorza Wielkiego, 1986.

16. Wiesiołek Alojzy o., Właściwe i niewłaściwe korzystanie z Pisma św. wedtug Klemensa z Aleksandrii, 1986.

17. Wróbel Zbigniew ks., Św. Augustyn, ,,Troska o zmartych”. Wstęp, ttumaczenie, komentarz, 1986.

18. Błasiński Józef ks., Nauka o Kościele św. Augustyna w „Homiliach na Ewangelię i Pierwszy List św. Jana”, 1987.

19. Giergiel Marek ks., Miłość Boża w „Enarrationes in Psalmos” św. Augustyna, 1987.

20. Hawryluk Wojciech M. ks., Wstęny etap ksztattowania postawy wiary jako fundament życia chrześcijańskiego w „,Katechezach” Cyryla Jerozolimskiego, 1987.

21. Karaś Jan ks., „,Metanoia” w „,Stromatach” Klemensa Aleksandryjskiego, 1987.

22. Kasyna Wojciech ks., Posty a miłość bliźniego w „Mowach” Leona Wielkiego, 1987.

23. Klucznik Jan ks., Nauka św. Grzegorza z Nazjanzu o chrzcie na podstawie jego „Mów”, 1987.

24. Kołtun Jerzy ks., Tytuły chrystologiczne $w$ dziele św. Augustyna „In Johannis Evangelium tractatus CXXIV", 1987.

25. Kuźmiak Eugeniusz ks., „Enkrateia” w „Stromatach” Klemensa Aleksandryjskiego, 1987.

26. Laskowski Sławomir ks., Uobecnienie ekonomii zbawienia w Kościele wg I Księgi „Pedagoga” Klemensa Aleksandryjskiego, 1987.

27. Podborny Piotr ks., Tytuly chrystologiczne $w$ dziele Orygenesa „,Komentarz do Ewangelii św. Jana”, 1987.

28. Sośnicki Marek S. ks., Istota i źródło mądrości wedtug „,Stromatów” Klemensa Aleksandryjskiego, 1987.

29. Sroka Andrzej ks., „Apatheia” w „Stromatach” Klemensa Aleksandryjskiego, 1987.

30. Stępniak Janusz A., Problem nadziei w ,Stromatach” Klemensa Aleksandryjskiego, 1987. 
31. Wowk Dariusz ks., „Martyria” w „Stromatach” Klemensa Aleksandryjskiego, 1987.

32. Kowalski Aleksy ks., Helleńska koncepcja człowieka w „,Stromatach” Klemensa Aleksandryjskiego, 1988.

33. Paciorek Piotr ks., ,,Scriptura Dei” w „Enarrationes in Psalmos” św. Augustyna, 1988.

34. Rzodkiewicz Leopold ks., Tytuły chrystologiczne $w$ „,Stromatach” Klemensa Aleksandryjskiego (Księgi I - III), 1988.

35. Jakubiak Gerard ks., Chrystocentryzm w dziele św. Ambrożego „Expositio Evangelii secundum Lucam”, 1989.

36. Kwaśniewski Jarosław ks., Miłość chrześcijańska w „Mowach” Leona Wielkiego, 1989.

37. Laskowski Sylwester ks., Matżeństwo i celibat laikatu w pismach Tertuliana, 1989.

38. Papierz Stanisław ks., ,,Modlitwa serca” w „Enarrationes in Psalmos” św. Augustyna, 1989.

39. Kowalski Zbigniew ks., Wiara w ujęciu św. Augustyna na podstawie jego „Homilii do Ewangelii i Pierwszego Listu św. Jana”, 1990.

40. Kwiatkowski Krzysztof ks., Nadzieja chrześcijańska w „Enarrationes in Psalmos"św. Augustyna, 1990.

41. Melko Piotr ks., Chrystologia Orygenesa w „Homiliach o Księgach Rodzaju, Wyjścia, Kapłańskiej, Liczb, Jozuego, Sędziów”, 1990.

42. Tomczyk Edward ks., Grzech źródłem wielorakich cierpień grzesznika według „Enarrationes in Psalmos”'sw. Augustyna, 1990.

43. Arbaczewski Andrzej ks., Mądrość w „Enarrationes in Psalmos” św. Augustyna, 1991.

44. Bednarz Jacek ks., Bojaźń Boża w „Enarrationes in Psalmos” św. Augustyna, 1991.

45. Bielecki Mirosław ks., Chrześcijanie wobec świata pogańskiego w świetle „, Kata Kelsu” Orygenesa, 1991.

46. Dwayne Allen Franciszek ks., Nauka o pięknie w pismach Klemensa Aleksandryjskiego, 1991.

47. Kudelski Bogdan ks., Problematyka biblijna w „De civitate Dei” św. Augustyna, 1991.

48. Kwintal Krystyna, Obraz prześladowań chrześcijan na podstawie pism apologetów łacińskich, 1991.

49. Mikulska Anna, Ideat kobiety w ,Stromatach” Klemensa Aleksandryjskiego, 1991.

50. Przybyła Leszek ks., Ideał doskonałości chrześcijańskiej w „Homiliach do Ewangelii św. Mateusza” Jana Chryzostoma, Lublin 1991.

51. Sokołowski Wojciech ks., Model doskonałości chrześcijańskiej w „Mowach” Grzegorza z Nazjanzu, Lublin 1991.

52. Wójcik Jarosław E. ks., Problem zła i dobra w „,De civitate Dei” św. Augustyna, 1991.

53. Zdybel Henryk ks., Model życia monastycznego w „Apoftegmatach” Ojców Pustyni, 1991. 
54. Zieliński Ryszard ks., Charakterystyka chrześcijan na podstawie dzieł apologetycznych Tertuliana, 1991.

55. Bajdo Ryszard ks., Aurelius Augustinus: „De moribus Ecclesiae Catholicae”. Wstep i ttumaczenie, Lublin 1992.

56. Bednarski Józef ks., Wiara, nadzieja i miłość $w$ „,Wykładzie do Ewangelii św. Łukasza” Ambrożego z Mediolanu, 1992.

57. Boś Małgorzata, Obraz „,walki duchowej” chrześcijanina w homiliach Orygenesa do ksiag: Rodzaju, Wyjścia, Kapłańskiej, Liczb, Sędziów i Jozuego, 1992.

58. Drozd Ryszard ks., Program doskonalenia chrześcijańskiego w „, Komentarzach do Ewangelii św. Jana” Orygenesa, 1992.

59. Flak Mirosław T. ks., Model doskonałości chrześcijańskiej w „Homiliach o Księdze Rodzaju, Wyjścia i Kapłańskiej” Orygenesa, 1992.

60. Król Bogdan ks., „Motyw serca” w „Enarrationes in Psalmos” św. Augustyna, 1992.

61. Leńczuk Julian ks., Model doskonałości chrześcijańskiej na podstawie „Dialogów” Grzegorza Wielkiego, 1992.

62. Maciejewski Dariusz A. ks., Angelologia św. Augustyna w świetle „Enarrationes in Psalmos", 1992.

63. Mazurek Sławomir ks., Kler zakonny i diecezjalny w „Listach” Grzegorza Wielkiego, 1992.

64. Muda Jan E. ks., Koncepcja miłości chrześcijańskiej św. Augustyna w „Homiliach do Ewangelii św. Jana”, 1992.

65. Nawrot Jan ks., Nauka o cnotach w „Apoftegmatach” Ojców Pustyni, 1992.

66. Paluch Wojciech ks., Pismo święte w „Homiliach o Księdze Rodzaju, Wyjścia i Kaptańskiej” Orygenesa, 1992.

67. Semeniuk Jan ks., Wartość nauki chrześcijańskiej w świetle „Kata Kelsu” Orygenesa, 1992.

68. Smyl Kazimierz ks., Model doskonałości chrześcijańskiej w „Mowach” św. Augustyna, 1992.

69. Traczykiewicz Andrzej A. ks., Nauka o miłości chrześcijańskiej w pismach Maksyma Wyznawcy, 1992.

70. Wierzbińska Dorota, Chrystocentryzm w „Mowach” Leona Wielkiego, 1992.

71. Bazychowska Elżbieta, Cierpliwość chrześcijańska $w$ „Enarrationes in Psalmos" św. Augustyna, 1993.

72. Chrościński Grzegorz, Problematyka teologiczna listów Teodoreta z Cyru, 1993.

73. Denys Stanisław ks., Program doskonalenia chrześcijańskiego w „Sermones” Cezarego z Arles, 1993.

74. Dudkiewicz Tomasz ks., Nauka o życiu wiecznym w „,Mowach” Grzegorza z Nazjanzu, 1993.

75. Gil Adam ks., Tytuly chrystologiczne w „Enarrationes in Psalmos” (1-50) św. Augustyna, 1993.

76. Kalejta Grzegorz, Nauka o grzechu w „, Collationes Patrum” Jana Kasjana, 1993.

77. Kisieliński Jarosław ks., ,Entole” w „,Stromatach” Klemensa Aleksandryjskiego, 1993.

78. Klibengajtis Ewa, Program doskonalenia chrześcijańskiego w „Stromatach” Klemensa Aleksandryjskiego, 1993. 
79. Łukasik Jan M. ks., Postulaty ascezy wczesnochrześcijańskiej w listach św. Hieronima, 1993.

80. Sochacki Paweł ks., Tytuty chrystologiczne w „Enarrationes in Psalmos” (51 100) św. Augustyna, 1993.

81. Szczur Piotr ks., Tytuty chrystologiczne w ,Enarrationes in Psalmos” (101 - 150) św. Augustyna, 1993.

82. Śledź Krzysztof ks., Nauka o grzechu w świetle „Homilii do Ksią: Rodzaju, Wyjścia i Kapłańskiej” Orygenesa, 1993.

83. Wołoszyn Andrzej C. ks., Obraz człowieka w „,De civitate Dei” św. Augustyna, 1993.

84. Wójcik Joanna, Tytuły chrystologiczne w „Mowach” Leona Wielkiego, 1993.

85. Wróblewski Marian ks., Model formacji kapłańskiej w nauce św. Grzegorza z Nazjanzu i św. Jana Chryzostoma, 1993.

86. Zblewski Andrzej ks., Aretologia św. Ambrożego w świetle „, Wykładu Ewangelii wedtug św. Łukasza”, 1993.

87. Grzyb Zbigniew ks., Ideat matżeństwa i rodziny w „Mowach” św. Grzegorza z Nazjanzu, 1994.

88. Niedźwiecki Wojciech ks., Sprawiedliwość w „Homiliach na Ewangelie i Pierwszy List św. Jana” u św. Augustyna, 1994.

89. Pitucha Bogusław ks., Ekshortacje pastoralne w „Mowach” Leona Wielkiego, 1994.

90. Soniak Dariusz ks., Program doskonalenia chrześcijańskiego w „Homiliach o Ewangelii św. Lukasza” Orygenesa, 1994.

91. Wiśniewski Ryszard ks., Bojaźń Boża wedtug „,Stromateis” Klemensa Aleksandryjskiego, 1994.

92. Wólczyński Henryk ks., Postawa mnichów egipskich wobec bliźnich w świetle „,Verba seniorum”, 1994.

93. Antoniak Jarosław o., Cuda w nauczaniu św. Augustyna w świetle „In Johannis Evangelium tractatus", 1995.

94. Ciesielski Wojciech ks., Wykład Ewangelii wedtug św. Łukasza, 1995.

95. Ciupa Piotr, Głoszenie Ewangelii w świetle „Enarrationes in Psalmos” św. Augustyna, 1995.

96. Gola Andrzej ks., Ekshortacje pastoralne w świetle dzieła św. Augustyna „Homilie na Ewangelię i Pierwszy List św. Jana”, 1995.

97. Górski Bogdan ks., Kerygmat w „Stromatach” Klemensa Aleksandryjskiego, 1995.

98. Król Henryk ks., Chrystus w życiu chrześcijan w świetle dzieła św. Augustyna „Homilie na Ewangelię i Pierwszy List św. Jana”, 1995.

99. Opoń Bogdan, Askesis w pismach Klemensa Aleksandryjskiego, 1995.

100. Zieliński Ryszard o., Bogactwo i ubóstwo w świetle „Expositio Evangelii secundum Lucam” św. Ambrożego, 1995.

101. Buraczyński Adam, Miłość synteza życia i posłannictwa wg Konstytucji i Regut Kleryków Regularnych Somasków, 1996.

102. Girguś Wojciech, Nauka św. Ambrożego o małżeństwie i rodzinie na podstawie „,Wykładu Ewangelii wedtug św. Łukasza”, 1996.

103. Jędrzejak Joanna s., Wychowawcza funkcja „,Reguty” św. Augustyna, 1996. 
104. Jędrzejewski Roman, Filozoficzno-teologiczne dowody Atenagorasa z Aten na zmartwychwstanie umartych, 1996.

105. Kruszyński Dariusz ks., Filanthropos theos w pismach Klemensa Aleksandryjskiego, 1996.

106. Bałaban Mychajło, Agape - agapeo wg „Komentarza do Ewangelii św. Mateusza" Jana Chryzostoma, 1997.

107. Fredyna Wołodymyr ks., Życie mnisze wedtug rad ewangelicznych $w$ rozumieniu Teodora Studyty, 1997.

108. Gąsecki Krzysztof ks., Ideat duszpasterza w czasach pontyfikatu św. Grzegorza Wielkiego w świetle jego korespondencji, 1997.

109. Górski Krzysztof ks., Program doskonalenia chrześcijańskiego w świetle homilii Orygenesa o Księdze Liczb, 1997.

110. Paczkowski Jurand ks., Tytuły chrystologiczne $w$ dziele „De civitate Dei” św. Augustyna, 1997.

111. Sieroń Roman ks., Radość wedtug „Stromatów” Klemensa Aleksandryjskiego, 1997.

112. Zagórski Dariusz ks., Tytuły chrystologiczne w „Hexaemeronie” św. Ambrożego, 1997.

113. Ziółkowska Marta, Mariologia św. Ambrożego w świetle „,Wykładu Ewangelii wedtug św. Łukasza”, 1997.

114. Biszko Władysław ks., Typologia starotestamentalna w „Homiliach do Ksiegi Liczb” wedtug Orygenesa; 1998.

115. Janowski Mirosław ks., Obraz życia monastycznego w świetle „,Księgi Starców”, 1998.

116. Kaczorski Jacek ks., Poglądy manichejczyków w świetle „C Contra Faustum” św. Augustyna, 1998.

117. Kowalik Monika, Św. Augustyna relacje międzyludzkie w świetle „,Wyznań”, 1998.

118. Kubasik Paweł M. ks., Tytuły chrystologiczne $w$ dziełach św. Augustyna: „De sermone Domini in Monte”, ,, De diversis questionibus ad Simplicianum ”, ,Questionum Evangeliorum", 1998.

119. Owczarek Mirosław ks., Program doskonalenia chrześcijańskiego w świetle ekshortacji pastoralnych świętego Augustyna (,Ennarationes in Psalmos” 1-50), 1998.

120. Romanowski Andrzej o., Nauka o męczeństwie w „Eis Martyrion Protreptikos” Orygenesa, 1998.

121. Siemiątkowski Wojciech H. ks., Nauka Orygenesa o miłości chrześcijańskiej w świetle „Komentarza do Listu św. Pawła do Rzymian”, 1998.

122. Ziemelis Aldis ks., Akcja charytatywna w świetle „Listów” św. Grzegorza Wielkiego, 1998.

123. Bryła Dariusz o., Seminarium patrystyczne KUL 1993-1998, 1999.

124. Jakielski Andrzej ks., Obraz Jezusa Chrystusa w świetle dzieła św. Augustyna „De consensu Evangelistarum”, 1999.

125. Ordon Piotr ks., Laudate Dominum w „Enarrationes in Psalmos” św. Augustyna, 1999.

126. Paderewski Piotr, Aretologia Leona Wielkiego wświetle jego mów, 1999. 
127. Staniszewski Ireneusz ks., Stużba Boża w parafii Podwyższenia Krzyża Świętego $w$ Tczewie w latach 1965-1995; 1999.

128. Wysocki Marek ks., Nauka Orygenesa o wierze w świetle jego „, Komentarza do Listu św. Pawła do Rzymian”, 1999.

129. Galikowski Tadeusz ks., Motyw dnia w ,Enarratationes in Psalmos” św. Augustyna, 2000.

130. Jankowski Piotr ks., Chrystologia w świetle dzieła św. Augustyna „In Joannis Evangelium tractatus (I-XLVI)", 2000.

131. Kwiatkowski Piotr ks., Chrystologia Ojców Kościoła w świetle czytań brewiarzowych, 2000.

132. Milewski Waldemar ks., Chrystologia św. Augustyna w świetle onomastyki „In Joannis Evangelium tractatus", 2000.

133. Dąbrowski Jerzy ks., „Pożądliwość” w sporze św. Augustyna z Julianem z Eklanu, 2001.

134. Gałązka Adam ks., ,, Quaestiones in Heptateuchum” św. Augustyna, 2001.

135. Gierko Mirosław ks., Lex Dei w „Enarrationes in Psalmos” św. Augustyna, 2001.

136. Fryc Tomasz ks., Aretologia św. Grzegorza Wielkiego w świetle jego „Homilii na Ewangelie", 2001.

137. Łepek Piotr ks., Oskarżenia chrześcijan i ich odparcie w świetle pism apologetycznych Tertuliana, 2001.

138. Stefański Leszek ks., Miłość-Agape w „Mowach” Grzegorza Teologa, 2001.

139. Szwal Jan ks., Odmienności występujace w czterech ewangeliach w świetle „De consensu Evangelistarum”św. Augustyna, 2001.

140. Topolski Tadeusz o., Imiona Maryi w łacińskich przekazach patrystycznych, 2001.

141. Wierzbicki Wojciech ks., Caritas-dilectio w wykładzie św. Augustyna do Ewangelii wedtug św. Łukasza, 2001.

142. Kamiński Adam ks., Wzór przyjaźni św. Bazylego Wielkiego ze św. Grzegorzem z Nazjanzu jako model naśladowczy dla współczesnej wspólnoty bazyliańskiej, 2002.

143. Nemcek Julius, Metoda egzegetyczna Teodoreta z Cyru w świetle „Komentarza do Listu św. Pawła Apostoła do Rzymian”, 2002.

144. Różyński Piotr, Superbia wedtug „Enarrationes in Psalmos” św. Augustyna, 2002.

145. Burdzy Krystian ks., Symbolika roślin w świetle „Enarrationes in Psalmos” św. Augustyna (I-LXXV), 2003.

146. Czajkowski Krzysztof ks., Symbolika zwierząt wedtug „Enarrationes in Psalmos" św. Augustyna (I-LXXV), 2003.

147. Dudek Eligiusz ks., Model życia eremickiego w świetle „Apoftegmatów” Ojców Pustyni, 2003.

148. Kuliński Marek ks., Aretologia Maksyma Wyznawcy w świetle jego dzieła „,Kefalaia peri agapes", 2003.

149. Sobczyk Mariusz, Post jako forma ascezy mniszej na podstawie „Apoftegmatów” Ojców Pustyni, 2004.

150. Kelman Mirosław ks., Nauka o przyjaźni według „,Stromateis” Klemensa Aleksandryjskiego, 2005. 
151. Krukowski Krzysztof ks., Tytuły chrystologiczne w „Mowach” św. Grzegorza z Nazjanzu (Mowy I-XXV), 2005.

152. Siedlecki Ryszard ks., Ekshortacje pastoralne w kazaniach św. Cezarego z Arles, 2005.

153. Zarzeczny Tomasz, Program doskonalenia chrześcijańskiego według Orygenesa w świetle jego „Homilii o Ewangelii św. Łukasza”, 2007.

154. Karwasz Jacek ks., Program doskonalenia chrześcijańskiego w świetle patrystycznych ekshortacji pastoralnych występujacych w Liturgii Godzin (tom III), 2008.

155. Klępka Paweł ks., Jana Chryzostoma nauka o postach w świetle jego „Homilii na Ewangelię wedtug św. Mateusza”, 2008.

156. Szczeblewski Dawid ks., Program doskonalenia chrześcijańskiego w świetle patrystycznych ekshortacji wystepujacych w Liturgii Godzin (Tom 1), 2008.

157. Wójcik Krzysztof J. ks., Zarzuty kierowane pod adresem chrześcijan i ich odparcie wświetle „Apologii” świętego Justyna, 2008.

158. Zarzeczny Zbigniew P. ks., Program doskonalenia $w$ świetle kazań $i$ homilii Chromacjusza z Akwilei, 2008.

159. Ochal Piotr ks., Troska o ubogich w świetle komentarza Ambrożego z Mediolanu do Ewangelii wedtug świętego Łukasza, 2009.

160. Aleksandrowski Andrzej ks., Miłość chrześcijańska w świetle „, Kefalaia peri agapes" Maksyma Wyznawcy (1-200), 2011.

161. Flis Krzysztof ks., Funkcje filozofii $w$ świetle „, Stromateis” Klemensa Aleksandryjskiego, 2011.

162. Filipczuk Łukasz, Integralny charakter miłości chrześcijańskiej wedtug Klemensa Aleksandryjskiego, 2012.

163. Woelke Marcin ks., Opera charitatis. Dobroczynność chrześcijańska w świetle „XL Homiliarum in Evangelia” św. Grzegorza Wielkiego, 2012.

164. Sowa Marcin, Dobroczynność chrześcijańska w świetle mów św. Leona Wielkiego Papieża, 2013.

165. Sokołowski Radosław ks., Droga doskonalenia chrześcijańskiego w świetle „XL Homiliarum in Evangelia” świętego Grzegorza Wielkiego, 2014.

Zebrał ks. Marcin Wysocki, Lublin - KUL 